\title{
Function and behaviour: use-wear evidence from Upper Paleolithic tools in southern Shanxi Province, North China
}

\author{
Hong Chen ${ }^{1}$, Yiren Wang ${ }^{2}$ and Chun Chen ${ }^{3}$ \\ 1 Department of Cultural Heritage and Museology, Zhejiang University, Hangzhou, CN \\ 2 Shanxi Provincial Institute of Archaeology, Taiyuan, CN \\ 3 Department of Cultural Heritage and Museology, Fudan University, Shanghai, CN \\ hollychen@zju.edu.cn
}

\begin{abstract}
Lithic use-wear analysis has become a principal approach for interpreting the function of stone tools and inferring human behaviour. This study presents the results of use-wear analysis on lithic tools excavated from the Upper Paleolithic sites of Xiachuan and Chaisi in the southern part of Shanxi Province, North China. In this study, microblades and so-called core-like tools from these two sites were selected for examination by low-power techniques to identify their use patterns. The results suggest that approx. 30\% of microblades might have been used mainly to process animal substances, and a lower percentage for vegetal substances. Based on the use-wear evidence, items classified as core-like tools should be regarded as microblade-cores, since they exhibit few traces of utilisation.

IZVLEČEK - Analiza sledov uporabe kamnitih orodij je postala osnoven pristop pri razlagi funkcije kamnitih izdelkov in pri razlagi človekovih vedenjskih vzorcev. V̌studiji predstavljamo rezultate analize uporabe na kamnitih orodij, ki so bili izkopani na mlajše paleolitskih najdiščih Xiachuan in Chaisi v južnem delu province Shanxi na severu Kitajske. Za prepoznavanje sledov uporabe s pomočjo stereomikroskopa smo izbrali vzorce majhnih rezil in orodij, ki so podobna jedrom. Rezultati kažejo, da je bilo okoli 30\% mikro-rezil uporabljenih pri predelavi živali; orodja, ki so podobna jedrom, pa predstavljajo verjetno jedra, iz katerih so lomili in izdelovali rezila, saj kažejo le zelo redke sledove uporabe.
\end{abstract}

KEY WORDS - Upper Paleolithic; Xiachuan and Chaisi sites; tool function; use-wear analysis

\section{Introduction}

Stone tools are widely regarded as good indicators of the development of intelligence, technique, $\operatorname{cog}$ nition and adaptability of prehistoric people, because hunter-gatherers would have developed different strategies to cope with climate fluctuations, environmental changes and constraints on available resources in different areas. In accordance with the châine opératoire concept (Schiffer 1972; Sellet 1993), stone material, its production, use, repair, and waste, and every step of its utilisation are closely related to its function. Research into the function of stone tools is thus an important way to understand prehistoric human behaviour and subsistence strategies, and can also provide a new perspective for interpreting the development of human adaptations and social organisation.

Use-wear analysis is a method developed by archaeologists to infer the function of a tool on the basis of microscopic traces of wear left on its edges or surfaces. Since the introduction of Sergei Semenov's translated English monograph Prehistoric Techno$\log y$ (1964), use-wear analysis has become a principal approach for interpreting the function of stone 
tools in Europe and North America. There are two major techniques for lithic use-wear analysis. One is the high-power technique proposed by Larry Keeley (1980), which concentrates on the formation and distribution of use polish at relatively high magnifications (100-400x) under either incident light microscopes or scanning electron microscopes (SEM). The other is the low-power technique, advocated by Ruth Tringham et alii (1974) and George Odell (1979) that focuses on traces of edge-damage, microscopic fracturing and abrasion visible at relatively low magnifications (5-200x) under reflective-light stereoscopic microscopes. After decades of experiment and practice, it has been shown that each use-wear technique has its own particular advantages and weakness (Shea 1987), and analysts often use both highand low-power techniques in one analysis (UngerHamilton 1989; Grace 1996).

The Xiachuan and Chaisi sites are important Upper Paleolithic sites in northern China (Fig. 1) with a microblade-dominated industry. The Xiachuan site was discovered in 1970 in southern Shanxi Province. Two cultural layers separated by a sterile layer were identified. It is reported that more than 1800 stone artefacts were excavated from the upper cultural layer in the 1973-1975 excavations (Wang et al. 1978). In addition, 4415 stone artefacts were collected from other localities at Xiachuan between 1990 and 1992 (Chen 1996). Abundant microliths were found in the upper layer, including end-scrapers, backed-knives, burins, points, microblades and microblade-cores. According to radiocarbon dating, the age of the upper layer of Xiachuan site is estimated between 23000 BP (Tang 2000; Kuzmin 2007) and 13900 BP (CASS 1991). The Chaisi Site, also known as Locality 77:01 at Dingcun, was found in 1977 on the second terrace of the Fenhe River near Chaisi in Xiangfen County, Shanxi Province. The excavation in 1978 yielded numerous microblade remains and a few large chipping stone tools (Wang 1986; Wang et al. 1994). There are two radiocarbon dates for the site: 26 $495 \pm 590 \mathrm{BP}$ and $40000 \mathrm{BP}$ ( $\mathrm{Li}$ 1993). The excavator of this site argued that the former date is reasonable, particularly for the microblade remains (Wang 1986). It has been suggested that the lith- ic assemblage of Chaisi might have been the predecessor of that at Xiachuan (Wang et al. 1994; Zhang 2003).

The function of stone tools has been a popular topic for prehistoric archaeologists. However, archaeological research on the stone artefacts from Xiachuan and Chaisi have so far focused only on their morphological features or manufacturing techniques. In this study, some artefacts from the two sites were selected for use-wear analysis to explore how the tools might have been employed and what materials might have been exploited.

\section{Methods and materials}

Use-wear analysis has emerged as one of the principal methods for interpreting the functions of stone tools. The low-power technique has been employed in several studies and in the past two decades has been proven to be a reliable method for interpreting uses of stone tools (Shen 2001; Zhang et al. 2010; Gao, Shen 2008; Chen et al. 2010). The low-power technique has a number of advantages. First, it is a reliable means of assessing the use-task of stone tools by identifying edge damage, as well as detecting polish and striations. Second, since observation of implements takes less time, this technique is suitable for examining a large number of artefacts in a limited time. Third, it has great potential for studying other material, such as bones and jade (Potts, Shipman 1981; Bromage, Boyde 1984; Zhang et al. 2002). Fourth, for most analysts, the equipment needed for this technique is not expensive.

We thus employed the low-power technique in this study, using an Olympus SZX12-3131 stereoscopic

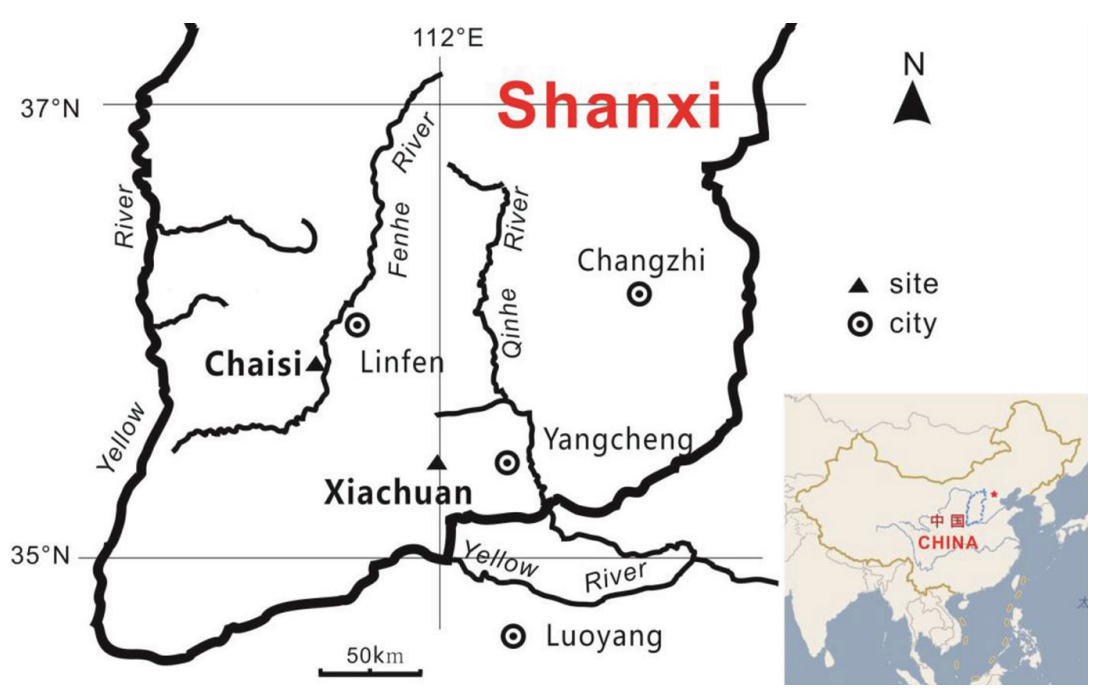

Fig. 1. Location of the Xiachuan and Chaisi sites. 

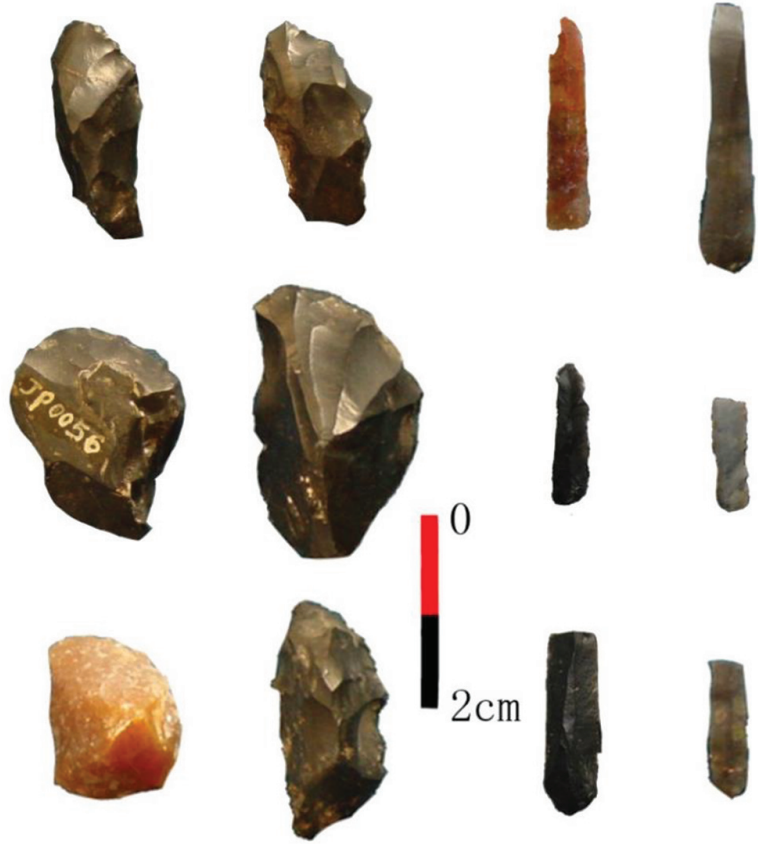

core-like tools
Fig. 2. A piece of the observed specimens from the Xiachuan and Chaisi sites.

microscope with a magnification between $3.5 \mathrm{x}-144 \mathrm{x}$, to focus on evidence of micro-fractural scarring and edge rounding through use-wear. Polish and striation wear patterns were also observed if possible. After a preliminary examination, some artefacts from Xiachuan and Chaisi were selected for further analysis because they showed indications of use-wear. A total of 93 specimens were observed and analysed (Fig. 2), including 19 from Xiachuan (11 microblades and 8 core-like tools) and 74 from Chaisi (63 microblades and 11 core-like tools). The main raw materials of these specimens are black or yellow chert.

\section{Results}

The term 'functional unit' (FU) was used to describe the segment of the working edge, including both usewear and hafting or prehensile wear. The analytic

\begin{tabular}{|l|c|c|c|c|}
\hline & \multicolumn{2}{|c|}{ XIACHUAN } & \multicolumn{2}{c|}{ CHAISI } \\
\hline Tool Motion & $\mathbf{N}$ & $\%$ & $\mathbf{N}$ & $\%$ \\
\hline cut/saw & 5 & 62.5 & 15 & 62.5 \\
\hline slice & 1 & 12.5 & 2 & 8.3 \\
\hline scrape & 1 & 12.5 & 4 & 16.7 \\
\hline prehensive & 1 & 12.5 & 0 & 0 \\
\hline hafting & 0 & 0 & 3 & 12.5 \\
\hline total FU & 8 & 100 & 24 & 100 \\
\hline
\end{tabular}

Tab. 1. Tool motion at the Xiachuan and Chaisi assemblages. results suggest that $27.96 \%$ of specimens show usewear $(\mathrm{N}=26)$. Most tools display more than one $\mathrm{FU}$. Therefore, 32 FUs were found in different locations on 26 used specimens.

For the Xiachuan specimens, five microblades and one core-like tool show positive use-wear. Eight FU's were identified. Four types of tool motion were inferred: cutting or sawing (up to 62.5\%), slicing, scraping, and gripping (Tab. 1). Contact materials commonly range from soft to hard animal substances such as flesh, fresh hide, dried hide, and fresh bone (Tab. 2). From a cross-tabulation of tool motion and contact material, the use-tasks comprised cutting or sawing flesh $(\mathrm{N}=2)$, cutting or sawing hide $(\mathrm{N}=3)$, slicing flesh $(\mathrm{N}=1)$, and scraping hide $(\mathrm{N}=1)$.

On the Chaisi specimens, 24 FUs were identified on 20 specimens, including 15 certain and 9 uncertain types of use-wear. Three pieces retain a prehensile area associated with a working surface on edges. Use-wear was also identified on a number of microblades, accounting for $31.7 \%$, while no use-wear was found on the core-like tools. Use-wear on blades or microblades indicated that these artefacts were used for cutting/sawing, slicing, scraping, and hafting (Tab. 1). Most of the use-wear was related to animal substances of varying hardness, while $8.3 \%$ were associated with vegetal substances (Tab. 2). Animal butchering, flesh processing and hide processing might have been the main tasks for the occupants of Chaisi; for instance, two use-wear FU's show the feature as a result of simultaneous contact with both flesh and bone. Three segments of micro-scars in a discontinuous distribution on the edges of microblades appear different from the scars caused by processing hard substances. It is inferred that these microblades were inset in a medium-hard material such as bone or fresh wood, and used as a composite tool with a hafted shaft, because the identifying features are similar to those simulated in previous experiments (Zhao et al. 2008).

\begin{tabular}{|l|c|c|c|c|}
\hline & \multicolumn{2}{|c|}{ XIACHUAN } & \multicolumn{2}{c|}{ CHAISI } \\
\hline Contact Material & $\mathbf{N}$ & $\%$ & $\mathbf{N}$ & $\%$ \\
\hline flesh & 2 & 25 & 4 & 16.7 \\
\hline fresh hide & 3 & 37.5 & 2 & 8.3 \\
\hline dried hide & 1 & 12.5 & 3 & 12.5 \\
\hline bone & 1 & 12.5 & 7 & 29.2 \\
\hline vegetal & 0 & 0 & 2 & 8.3 \\
\hline uncertain & 1 & 12.5 & 6 & 25 \\
\hline total FU & 8 & 100 & 24 & 100 \\
\hline
\end{tabular}

Tab. 2. Contact materials of the Xiachuan and Chaisi assemblages. 


\section{Discussion and summary}

In this study, we applied use-wear analysis to microscopically examine edge-damages and surface-rounding of specimens from the Upper Palaeolithic Xiachuan and Chaisi sites in order to assess how they were used. The analytic results reveal direct evidence of stone tool manufacturing and function. Those blades or microblades with straight and sharp edges might have been manufactured to be intentionally used as composite tools by being inset in a shaft. According to the evidence of functional analysis, the core-like tools should be re-classified as microblade cores rather than tools.

\section{Function of microblades}

The analytic results suggest that 5 pieces of microblades from Xiachuan and 20 pieces from Chaisi retain indications of use-wear, including 27 used wear FUs and 4 hafting wear FUs. Cutting and scraping are the main motions. Most of the corresponding contact materials were soft animal substances such as flesh and hide, and a few are hard animal substances such as bone. Only $27.8 \%$ of the microblades from Xiachuan had been used, which is lower than our previous expectations. Tracey Lu (1999) mentioned that by using high-power techniques she had found some use-wear on a few blades at Xiachuan that was similar to 'sickle gloss', a kind of use-wear often found on microliths in Southwest Asia. However, it is difficult to understand the features and details of this 'sickle gloss' on Xiachuan tools since no photographs have been published. Several microwear studies using the high-power technique have confirmed that the 'sickle gloss' might have been caused by processing cereals or seeds (UngerHamilton 1985; Goodale et al. 2010). As suggested by Jian-Zhong Sun et alii (2000), the climate of the Xiachuan site was slightly colder than today, which was suitable for abundant temperate plants and animals. The use-wear evidence also suggests that the occupants of Xiachuan might have exploited and processed animals as their principal food resources (Fig. 3). It is consistent with some scholars' speculation that the microblades were probably tools for exploiting animal substances in the particular conditions of the terminal Pleistocene, and were used by hunter-gatherers to respond to changes in the availability of resources during the Last Glacial Period (Chen 1994).

The percentage of use-wear on microblades from Chaisi is higher than that from Xiachuan. Since the upper layer at the Chaisi site was deposited before the Last Glacial period in MIS 3, the climate was warm and humid, and plants and animals were relatively abundant. On the basis of the use-wear analysis, animal-processing (Fig. 4, lower part) would also have been one of major tasks for people living at Chaisi. Moreover, a few results indicate vegetable processing (Fig. 4, right upper part) and might provide a picture of a dualistic structure of resource exploitation.

According to archaeological and ethnological research, microblades might be parts of composite tools which were inset in wooden or bone handles (Chard 1974; Sun 2003; Cui et al. 2010). At the Xiachuan and Chaisi sites, those microblades with a regular shape, appropriate size and suitable sharp edges might have been selected for use, while pieces that were too thick or small, and lacking sharp or straight edges would be discarded. The identification of the three hafting-wear FUs on the microblades (Fig. 4, left upper part) provides us with more reliable evidence for understanding how they were hafted or inset. The discovery of prehensile wear on

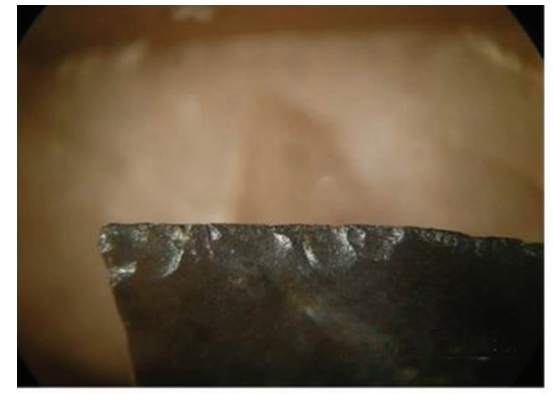

SP01162-D40X

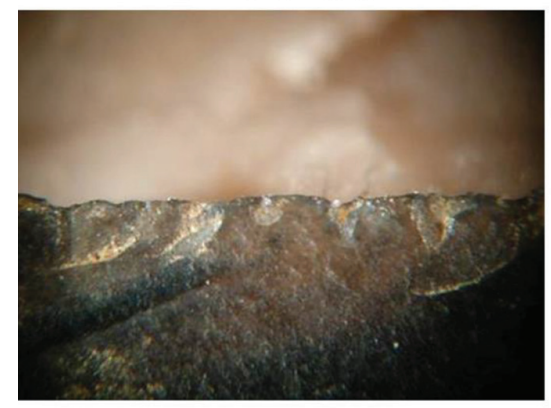

SP01211-D25X

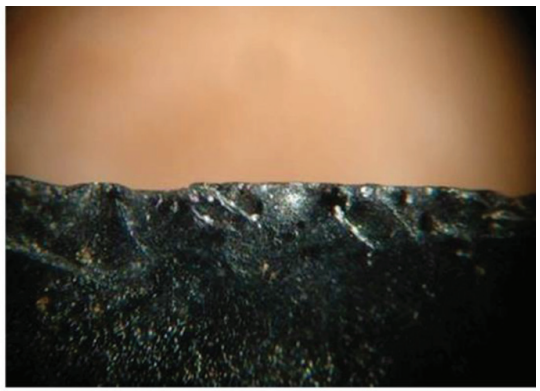

SP01431-D40X

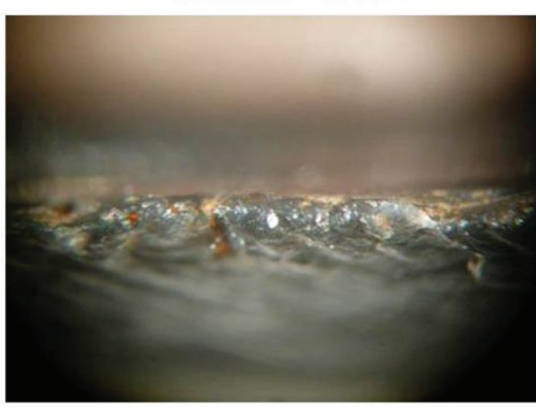

$\mathrm{SP} 01211-\mathrm{E} 25 \times$
Fig. 3. Use-wear observed on microblades from the Xiachuan site. 
blades is not accidental. In Xiao Zhang's dissertation (2009), she noted this phenomenon on one piece of blade from the Hutouliang site in the Nihewan Basin of North China. This tells us that there may have been an alternative mode in which some complete and large blades were directly used by hand rather than hafted.

After an overview of the usewear analysis on blades, we realised that the functions or worked materials in association with these kinds of artefact are various and diverse. Microblades might have been

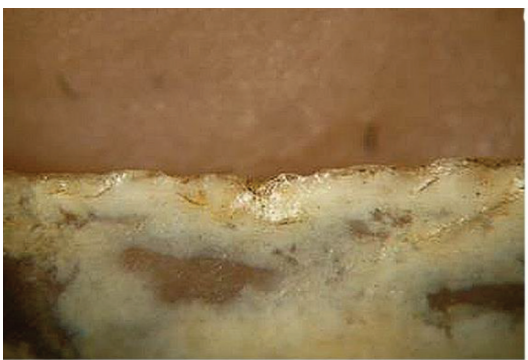

JP0012-D40X

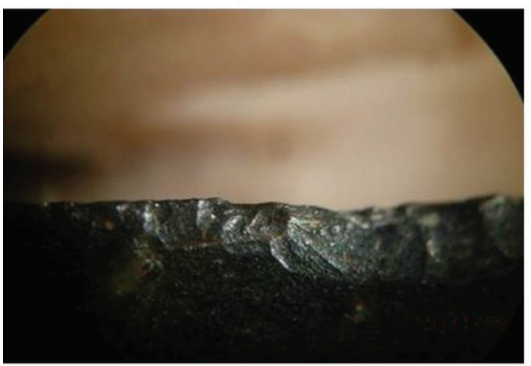

JP0217-D40×

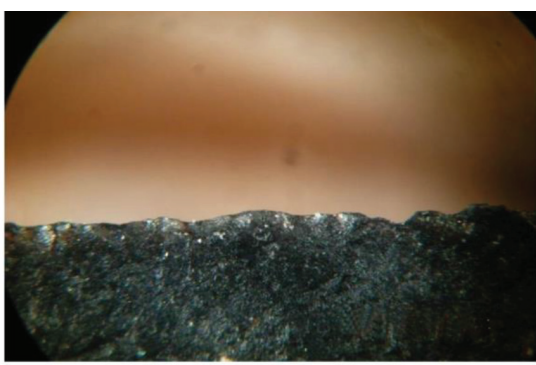

JP0115－D63×

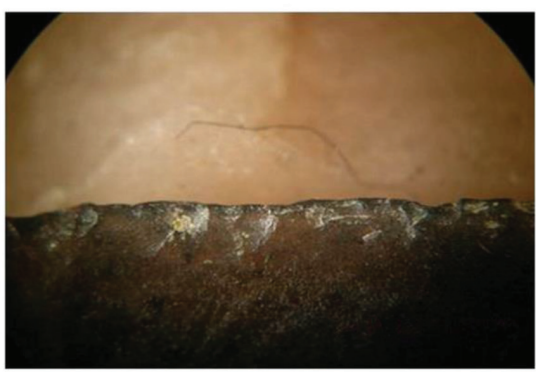

JP1956－V40×

Fig. 4. Use-wear observed on microblades from the Chaisi site. used for processing not only soft plants, but also the medium-hard parts of animals, hard woods or bone. Furthermore, the functions of microblades varied between different sites. More complex functions and tasks than we have hitherto understood might have involved microblades, which depends both on internal functional demands and external environmental conditions (Chen, Lian 2013).

\section{Function of core-like tools}

The group of core-like tools uncovered at both Xiachuan and Chaisi was classified as comprising a particular kind of stone artefacts. These specimens are made on thick flakes or tabulate cherts, and display continuously long and narrow scars similar to the working face of microblade cores. In terms of the shape of their edges, the excavators classified them into several subtypes, including oblique-edge shaped, flat-edge shaped, round-edge shaped, pointed, and so on (Wang et al. 1994). In the excavation report, the excavators classified these artefacts as core-like knives, which means they were considered as knives (Wang et al. 1978; 1994). However, our results demonstrate that only one specimen from the Xiachuan site was used as a tool, while the other seven specimens show no use-wear. Eleven specimens from the Chaisi site bear no usewear in association with usage or hafting.

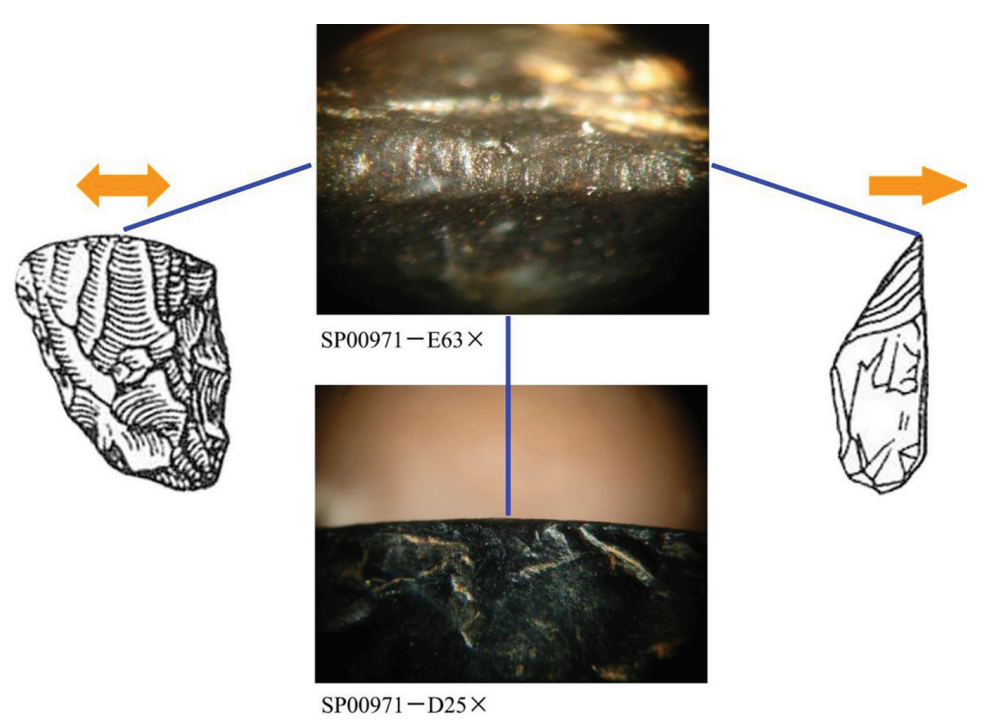

Fig. 5. Use-wear observed on a core-like tool.

Specimen SP00971 is a good example to indicate how this kind of artefact was used. Small scars with mostly feathered terminations mainly in continuous distribution appear on the convex edge (pc8-1), reduced from the ventral side to the back with heavy rounding. Both the sheet-shaped gloss and striation can be clearly seen; moreover, these striations are vertical to the edge (Fig. 5). This is clearly indicative of the object being employed for hide scraping. As a result, we recognised that this specimen was used as a scraper rather than as a so called core-like knife.

The original researchers classified these artefacts as tools rather than microblade-cores due to the microflaking scars on their edges, which were obviously 
produced by the impact with, or friction between, hard materials. The probable cause seems to trim the overhangs around the platform for the purpose of continued flaking. Therefore, we would like to classify these so called core-like knives as microblade-cores, rather than as a specific type of tool.

Some scholars have suggested that some wedge-shaped microblade-cores (Type I) at Hutouliang might have served the double functions of both tool and core (Zhu 2006). Zhang selected 52 microcores from the Hutouliang assemblage for use-wear analysis. As a result, it was demonstrated that only 12 specimens retain use-wear $(23.1 \%)$. On the one hand, the use-wear patterns found on two specimens within them might be caused by adhering to somewhere for flaking rather than being used for processing other materials. On the other hand, four FUs were determined to be caused by scraping or cutting, which is similar to specimen SP0097. Above all, the microblade cores (Type I) could not be classified as a kind of tool with an intentional design. These traces often appear on both edges of the back or bottom of the specimens, which were considered as probable locations on the microblade cores for fixing tightly and then for removing microblades later.

\section{Indications of human behaviour}

The Upper Paleolithic is identified as blade-dominated (Bar-Yosef 1999), including the technologies based on microblades in Northeast Asia, Siberia and North America, as well as geometric microliths in Europe and West Asia (Taylor 1962; An 2000). The emergence of microblades might indicate a technology or strategy adopted to explore animal resources by people living in extremely diverse and harsh environments (Chen 1984), which were closely connected with human migrations during the global climate changes in the Late Pleistocene (Chen 1984).
Based on the use-wear analysis of the lithic artefacts from the Xiachuan and Chaisi sites, we can gain some insights into human behaviour. On the one hand, the microblades with a regular shape, appropriate size and sharp edges might have been selected for use. Most of the use-wear could be related to animal substances, while a few might be associated with vegetal substances, which reveals a dualisticstructured strategy for exploiting resources. We suggest that most of the microblades might have been inserted into handles for use, while some complete and larger pieces might have been used freehand. On the other hand, the majority of core-like tools should be classified as microblade cores, while very few of them might have been used as tools with sharp edges from a functional perspective.

In summary, use-wear analysis can be used to connect the static archaeological record with the dynamic cultural context in which people operated in the past, and therefore it can play an essential role in linking human behaviour and natural processes to physical remains in the archaeological record. Usewear patterns can provide direct evidence of tool functions and material exploitation. This method in archaeological analysis might provide a new way to understand human activities in prehistory.

This research was supported by the National Social
Science Foundation of China (Grant No. 15CKG003),
the Provincial Science Foundation of Zhejiang (Grant
No. LY16D020001) and Zhijiang Junior Social Sci-
ence Scholars Program of Zhejiang Province. Many
thanks for the map and figures processed by Jun
Wang, who was a student at the Department of Cul-
tural Heritage and Museology at Zhejiang University.

\section{References}

An Z. M. 2000. Hundred years of discovery of Chinese microblades. Archaeology 5: 45-56. (in Chinese)

Bar-Yosef 0. 1999. The big deal about blades: Laminar technologies and human evolution. American Anthropologist 101(2): 322-338.

Bromage T. G., Boyde A. 1984. Microscopic criteria for the determination of directionality of cutmarks on bone. American Journal of Physical Anthropology 65(4): 359-366.
Chard C. 1974. Northeast Asia in Prehistory. University of Wisconsin Press. Wisconsin.

Chen C. 1984. The microlithic in China. Journal of Anthropological Archaeology 3(2): 79-115.

1994. The paleoenvironment of microblade remains in East Asia and North America. Quaternary Sciences 4: 369-377. (in Chinese) 
Chen Z. Y. 1996. New materials from the Xiachuan Site. Antiquity in Central China 4: 1-22. (in Chinese)

Chen C., An J. Y. and Chen H. 2010. Analysis of the Xiaonanhai lithic assemblage, excavated in 1978. Quaternary International 211: 75-85.

Chen H., Lian H. R. 2013. An overview of the use-wear analysis on blades. Steppe Cultural Relics 2: 125-131. (in Chinese)

Cui T. X., Yang Q., Yu J. C., Shuang L., Lin Zhou L. and Zhao C. H. 2010. Microwear analysis of a bone-handled microblade excavated at Shangzhai site in Beijing: Evidences from ESEM. Science China (Earth Sciences) 53(9): 1335-1342.

Gao X., Shen C. 2008. Archaeological Study of Lithic Usewear Experiments. Science Press. Beijing. (in Chinese)

Grace R. 1996. Use-wear analysis: The state of the art. Archaeometry 38: 209-229.

Goodale N. O. H., Andrefsky W. Jr., Kuijt I., Finlayson B. and Bart K. 2010. Sickle blade life-history and the transition to agriculture: an early Neolithic case study from Southwest Asia. Journal of Archaeological Science 37(6): 1192-1201.

Keeley L. H. 1980. Experimental Determination of Stone Tool Uses. The University of Chicago Press. Chicago.

Kuzmin Y. V. 2007. Geoarchaeological aspects of the origin and spread of microblade technology in northern and central China. In Y. V. Kuzmin, S. G. Keates and C. Shen (eds.), Origin and Spread of Microblade Technology in Northern Asia and North America. Archaeology Press of Simon Fraser University. Burnaby: 115-124.

Li Y. X. 1993. On the division of the Upper Paleolithic industries of China. Acta Anthropologica Sinica 12(3): 214-223. (in Chinese)

Lu T. L.-D. 1999. The Transition from Foraging to Farming and the Origin of Agriculture in China. British Archaeological Reports IS 774. Archaeopress. Oxford.

Odell G. H. 1979. A new improved system for the retrieval of functional information from microscopic observations of chipped stone tools. In B. Hayden (ed.), Lithic Use-Wear Analysis. Academic Press. New York: 329-344.

Potts R., Shipman P. 1981. Cutmarks made by stone tools on bones from Olduvai gorge, Tanzania. Nature 291: $577-$ 580 .

Schiffer M. 1972. Behavioral chain analysis: Activities, organization, and the use of space. Field Anthropology 65: 103-119.
Sellet F. 1993. Chaine operatoire: the concept and its applications. Lithic Technology 18: 106-112.

Semenov S. A. 1964. Prehistoric Technology. Cory, Adams and Mackay. London.

Shea J. J. 1987. On accuracy and relevance in lithic usewear analysis. Lithic Technology 16(2-3): 44-50.

Shen C. 2001. The Lithic Production System of the Princess Point Complex during the Transition to Agriculture in Southwestern Ontario, Canada. British Archaeological Reports IS 991. Archaeopress. Oxford.

Sun J. Z., Ke M. H. and Shi X. B. 2000. Palaeoclimatic Environments of the Xiachuan. Archaeology 10: 81-91. (in Chinese)

Sun Q. G. 2003. Study on the bone-handled microblade knives. Journal of National Museum of China 6: 12-20. (in Chinese)

Tang C. 2000. The Upper Paleolithic of North China: the Xiachuan Culture. Journal of East Asian Archaeology 2(12): 37-49.

Taylor W. E., 1962. A distribution between blades and microblades in the American Arctic. American Antiquity 27(3): 425-426.

CASS (The Institute of Archaeology, Chinese Academy of Social Science) 1991. Source on Radiocarbon Dates in Chinese Archaeology 1965-1991. The Cultural Relics Publishing House. Beijing. (in Chinese)

Tringham R. E., Cooper G., Odell G., Voytek B. and Whitman A. 1974. Experimentation in the formation of edge damage: a new approach to lithic analysis. Journal of Field Archaeology 1: 171-196.

Unger-Hamilton R. 1985. Microscopic striations on flint sickle-blades as an indication of plant cultivation: preliminary results. World Archaeology 17(1): 121-126.

1989. Method in Microwear Analysis: Prehistoric Sickles and Other Stone Tools from Arjoune, Syria. British Archaeological Reports IS 435. Archaeopress. Oxford.

Wang J. 1986. Problems of the date and cultural features of Xiachuan and Loc. 7701 of Dingcun site. Acta Anthropolgica Sinica 5(2): 172-177. (in Chinese)

Wang J., Wang X. Q. and Chen Z. Y. 1978. Xiachuan culture - Report of archaeological survey at Xiachuan in Shanxi Province. Acta Archaeologica Sinica 3: 259-288. (in Chinese) 
Wang J., Tao F. H. and Wang Y. R. 1994. A preliminary report on the surveys and excavations of the Paleolithic sites at Dingcun. Journal of Chinese Antiquity 3: 1-75. (in Chinese)

Zhang J. G., Yang Z. Y. and Chen Q. X. 2002. Observation and research on the tiny marks on the jades excavated in Lingjiatan. Southeast Culture 5: 16-27. (in Chinese)

Zhang X. L., 2003. Preliminary study on the typology of microliths at Locality 77:01 Dingcun and Xiachuan site. Wenwu Chunqiu 3: 1-11. (in Chinese)

2009. Stone Tool Function and Human Adaptive Behavior: Use-wear Analysis of Lithic Artifacts from the Hutouliang Site in northern China. Unpublished PhD thesis. The Graduate University of Chinese Academy of Sciences. Beijing. (in Chinese)

Zhang X. L., Shen C., Gao X., Chen F. Y. and Wang C. X. 2010. Use-wear evidence confirms the earliest hafted chipped-stone adzes of Upper Paleolithic in northern China. Chinese Science Bulletin 55(3): 229-236.

Zhao J. F. 2008. Review on the discovery at Locality S12 of the Shizitan site. Archaeological Studies 7: 223-231. (in Chinese)

Zhu Z. Y. 2006. The Study on Lithic Assemblage from the Hutouliang Site in North China. Unpublished PhD thesis. The Graduate University of Chinese Academy of Sciences. Beijing. (in Chinese) 